\title{
Haemolysis associated with diazoxide, used for the control of hypertension
}

\author{
R. A. BEST* \\ M.R.C.P. \\ H. M. CLINK $\dagger$ \\ M.R.C.Path. \\ * Department of Medicine and † Department of Haematology, St George's Hospital, \\ London $S W 1$
}

\begin{abstract}
Summary
Diazoxide, an agent used occasionally in the control of hypertension, has been associated with three haemolytic episodes in one patient. It is suggested that the mode of action is similar to that of diaminodiphenyl sulphone (dapsone) in acting as an oxidant stress to the ageing erythrocyte.

\section{Introduction}

Diazoxide, a non-diuretic benzo-thiadiazine, was originally developed for the treatment of hypertension. One of its side effects was found to be hyperglycaemia, and this has tended to limit its use and, in addition, leucopenia and thrombocytopenia have been described. Haemolysis has not previously been observed and we now wish to report such a case.
\end{abstract}

\section{Case summary}

A 26-year-old Nigerian came to England in 1958. Between 1962 and 1966 he was treated with antituberculous drugs for multiple abscesses, but in June 1969 he developed swelling in the right axilla and was admitted to another hospital, where a node biopsy of the right axilla produced acid-fast bacilli, and he was treated initially with PAS, isoniazid and pyrazinamide; the pyrazinamide and isoniazid were continued until June 1971. At this time he was found to have hypertensive heart failure with a blood pressure of $220 / 160 \mathrm{mmHg}$; an ECG showed left ventricular hypertrophy, the blood urea was $116 \mathrm{mg} \%$, and there was a trace of proteinuria.

His hypertension has proved very hard to control and thirteen different hypotensive agents have been tried during his four admissions-the first three for control of hypertension and the fourth, in October 1972, for left ventricular failure. Diazoxide has proved extremely useful in controlling his hypertension, but has, we believe, been directly responsible for a haemolytic anaemia on three separate occasions. These are summarized in Figs 1-3, and the dosage of diazoxide was as follows: episode $1,11.2 \mathrm{~g}$ over 37 days; episode 2, $9.9 \mathrm{~g}$ over 84 days; episode $3,3.0 \mathrm{~g}$ over 15 days.

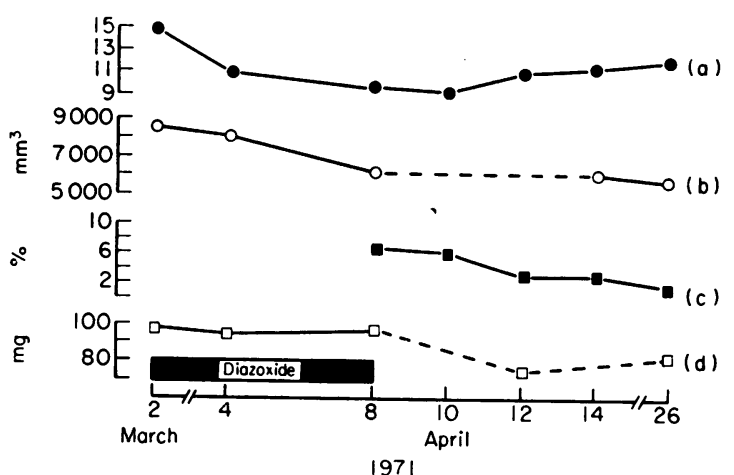

Fig. 1. Episode 1. Cell counts and urea levels, showing reticulocytosis associated with receovery of the haemoglobin following cessation of the drug. (a) Haemoglobin; (b) W.B.C.; (c) reticulocytes; (d) urea.

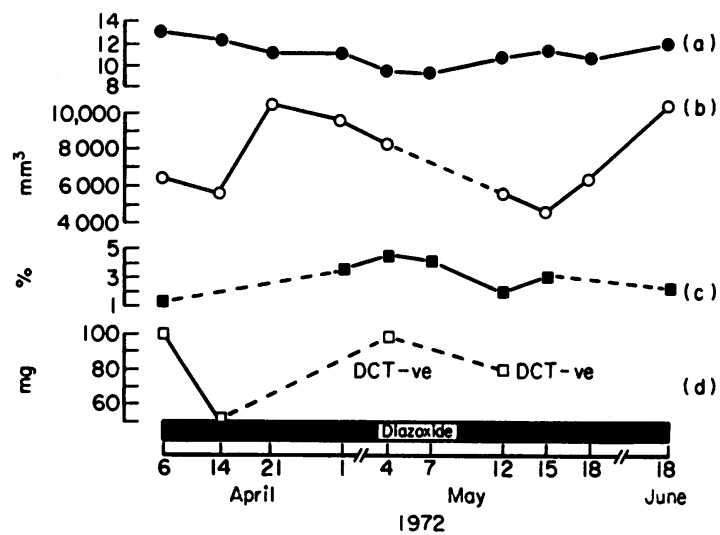

Fig. 2. Episode 2. Cell counts showing apparent compensatory state in association with continuous diazoxide.
(a) Haemoglobin;
(b) W.B.C.;
(c) reticulocytes;
(d) urea.

Several drugs were given concurrently, but their use did not coincide at all with the episodes and none of them was known to cause haemolysis (Table 1). Diazoxide was also given orally between May and August 1971, in a dose of $100 \mathrm{mg}$ t.i.d., twice weekly, and on this regime his haemoglobin had remained 


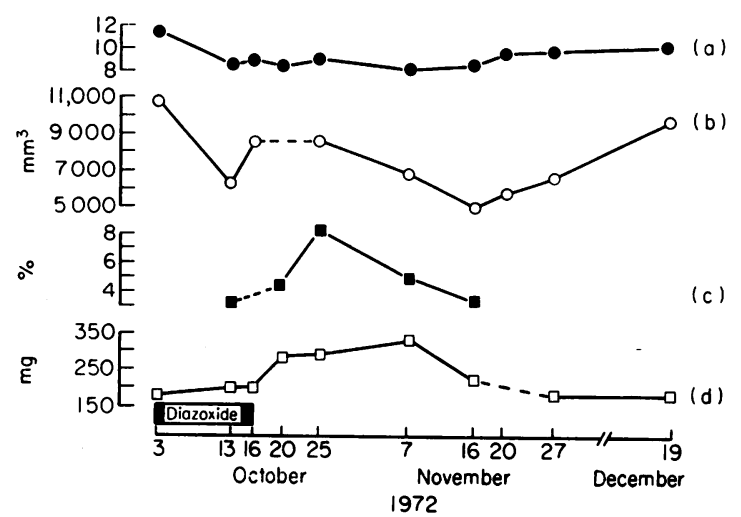

FIG. 3. Episode 3. Rapid fall in haemoglobin level associated with a short course of diazoxide. (a) Haemoglobin; (b) W.B.C.; (c) reticulocytes; (d) urea.

TABLE 1. Other drugs being administered to the patient in addition to diazoxide

\begin{tabular}{|c|c|c|}
\hline \multicolumn{3}{|c|}{ Episode } \\
\hline 1 & 2 & 3 \\
\hline Digoxin & Digoxin & Digoxin \\
\hline Hydrallazine & Hydrallazine & Hydrallazine \\
\hline Propranolol & Propranolol & Spironolactone \\
\hline Frusemide & Frusemide & Frusemide \\
\hline $\begin{array}{l}\text { Slow K } \\
\text { Pyrazinamide }\end{array}$ & Slow K & Propranolol \\
\hline INAH & & \\
\hline
\end{tabular}

constant at about $13 \mathrm{~g} \%$, white cell count at or above $5500 / \mathrm{mm}^{3}$ and reticulocytes between 1.6 and $2 \cdot 2 \%$.
A renal biopsy on 7 October 1960 showed membranoproliferative glomerulonephritis without evidence of amyloidosis.

\section{Haematological investigations}

The blood picture before treatment was normal. Haemolysis was unequivocally demonstrated by the finding of anaemia, reticulocytosis, absent haptoglobins and increased auto-haemolysis. The blood films showed occasional spherocytes and fragments (Fig. 4) but the leucocytes and platelets were never affected. The second and third episodes were equivalent to challenge with the drug and the degree of haemolysis has been proportional to the quantity and rate of diazoxide dosage. Subsequently, on a reduced intermittent dosage, haemolysis has not occurred. The haemoglobin level recovered more slowly on the third episode, possibly owing to the high blood urea which decreased slowly. No evidence was found of a coagulation defect.

GSH stability and glucose 6 phosphate dehydrogenase activity were normal, and the Direct Coombs' Test was repeatedly negative. Heinz bodies were observed during the first episode only, and only small quantities of urinary haemosiderin were demonstrated. Blood loss was excluded as were deficiency states.

Incubation of erythrocytes with solutions of diazoxide, at the concentration measured in the patient, were inconclusive, producing only small amounts of methaemoglobin. The levels were measured by the method of Symchowicz et al. (1967), and the level was as high as $14 \mathrm{mg} / 100 \mathrm{ml}$ of blood during the first

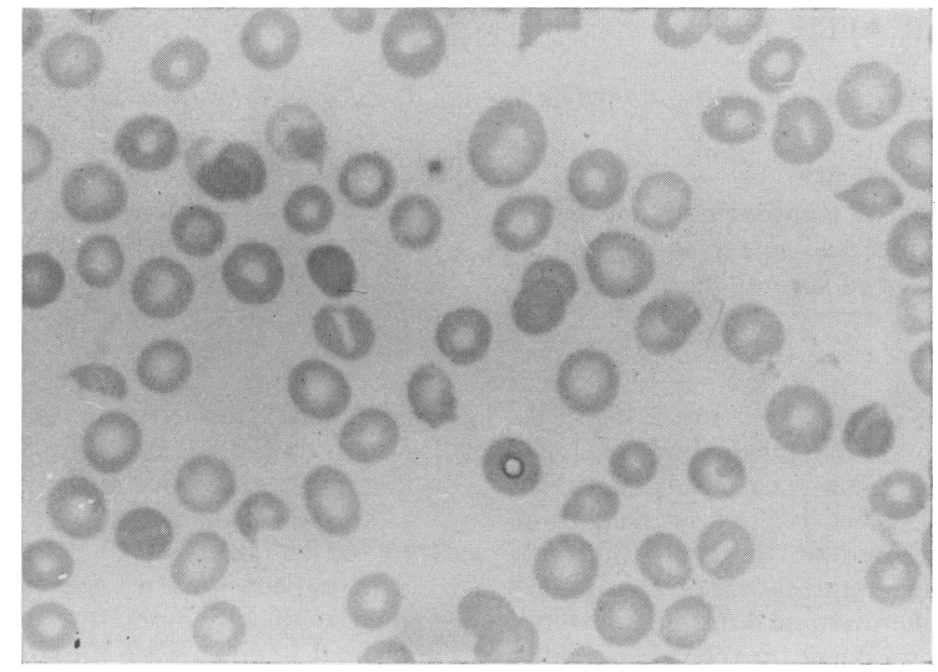

FIG. 4. Peripheral film, showing spherocytosis and fragmentation. 
episode. Cells were also incubated with dapsone, owing to its similar effect upon erythrocytes, again with inconclusive results.

\section{Discussion}

The administration of diazoxide to this patient has resulted in haemolysis on three occasions. On the first two of these, the fall in haemoglobin was of the order of 5-6 g over a time interval of about 6 weeks, and on the third $3.8 \mathrm{~g}$ in 2 weeks. In episode 2 the diazoxide was continued, and the haemoglobin was maintained at about $10 \mathrm{~g}$ in spite of this. Recovery followed the cessation of treatment and on a reduced maintenance dose, the blood picture has been satisfactory, showing only an occasional fragmented cell.

\section{Mode of action}

Diazoxide is similar in structure to chlorothiazide and to dapsone. The latter is well recognized as an oxidant haemolytic drug which will produce a compensated haemolytic state in normal people, probably owing to stress of the ageing red cell population, possibly mediated through the sulphone groups.

The oxidant agent may interfere with the membrane, or with glycolysis, leading to swelling and leakage with subsequent spherocytosis and fragmentation of the erythrocyte (Dacie, 1967).
The diazoxide was discontinued in the first episode, on account of the fall in haemoglobin, but it appears probable that a compensated haemolytic state would have been reached as, to some extent, occurred in episode 2. Diazoxide has a relatively long half-life, and is excreted in the urine. It is therefore probable that high levels of the drug may be reached in the plasma, particularly if there is any degree of renal failure.

Neutropenia and thrombocytopenia have been reported as a result of diazoxide therapy, but haemolysis has not previously been noted (Combs, Grunt and Brandt, 1967; Wales and Wolff, 1967). However, the latter authors report such a case in which a haemoglobin fall of $3.3 \mathrm{~g}$ occurred over 8 days and haemolysis would appear to be the likely explanation in this instance.

\section{References}

Combs, J.T., Grunt, J.A. \& BrandT, I.K. (1967) Hematological reactions to diazoxide. Pediatrics, 40, 90.

Davie, J.V. (1967) The Haemolytic Anaemias, 2nd edn, p. 1040. Churchill, London.

Symchowicz, S., Black, W.J., Smith, M., Calesnick, B. \& TABACHNICK, I.I.A. (1967) Diazoxide blood levels in man. Journal of Pharmaceutical Sciences, 56, 912.

WALES, J.K. \& WolfF, F. (1967) Haematological side effects of diazoxide. Lancet, i, 53.

\title{
Cytomegalovirus mononucleosis with urticaria
}

\author{
DAPHNE M. HUMPHREYS \\ M.B., M.R.C.P.* \\ Allan Myers \\ M.B., M.R.C.P. \\ * Royal Berkshire Hospital, Reading and The Royal Free Hospital, London
}

\begin{abstract}
Summary
A case of cytomegalovirus mononucleosis presenting with urticaria is described and so far as the authors know it is the first record of such an occurrence.

\section{Case history}

A 25-year-old woman presented on 19 October 1972, complaining of skin lesions for 5 days. Six days before admission to hospital she had developed lower retrosternal pain on swallowing, and the following day two patches of non-pruritic, nonpainful erythema appeared on the right thigh and later on the arms, fingers and face, and the lips became swollen. Chlorpheniramine $4 \mathrm{mg}$ t.i.d. lessened the swelling but had no effect on the other lesions. During the next 2 days the patches spread over the
\end{abstract}

legs and abdomen, and became painful and slightly itchy. Other symptoms included a sore throat for 3 days and central, colicky, abdominal pain associated with diarrhoea for 1 day. The only therapy before the onset of the rash was soluble aspirin and Benylin expectorant, and there had been no contact with known allergens.

Systematic enquiry was negative apart from symptoms of abdominal migraine as a child. There was nothing of significance in the family history.

\section{On examination}

The patient was a well nourished 25-year-old female with a temperature of $38.0^{\circ} \mathrm{C}$. The only abnormal findings were raised hot skin lesions over the arms, trunk and legs which closely resembled 